\title{
Correlation and Path Coefficient Analysis of Quantitative Traits in Some Wollega Coffee (Coffea arabica L.) Landrace in Western Ethiopia
}

\author{
Dawit Merga $^{1} \quad$ Hussein Mohammed $^{2} \quad$ Ashenafi Ayano $^{1}$ \\ 1.Ethiopian institute of Agricultural Research, Jimma Agricultural Research Center, P.O. Box 192, Jimma, \\ Ethiopia \\ 2.Hawassa University College of Agriculture, School of Plant and Horticultural Sciences, P.O. Box 5, Hawassa, \\ Ethiopia
}

\begin{abstract}
Arabica coffee is cash crop which plays great role in providing foreign exchange for Ethiopia. The twenty six coffee genotypes (22 accessions with four standard checks) were used during field experiment using Randomized Complete Block Design (RCBD) with three replications. The experiment was conducted with the objective to determine the association among quantitative traits of some wollega coffee genotypes. Quantitative data was taken for 23 traits of which 22 showed significant difference among coffee genotypes. Coffee bean yield had positive phenotypic and genotypic correlation with growth parameters such as Plant height $(\mathrm{PH})$, height up to first primary branch (HFPB), total node number (TNN), diameter of main stem(DM), number of primary branches (NPB), number of bearing primary branches (NBPB), percentage of bearing primary branches (PBPB) and canopy diameter (CD). From path coefficient analysis of CD, fruit width and fruit thickness showed negative direct effect on yield. This implies that indirect selection of these traits via other traits for yield improvement is momentous. Average length of primary branch (ALPB), HFPB, TNN and NBPB had positive direct effect and positive phenotypic correlation ( $\mathrm{rp}=0.18,0.14,0.36,0.50$ respectively) with green bean yield. This revealed that selecting plants with high performance in these traits will lead to selection of plants with high yield. Thus, priority should be given for these traits during breeding program for yield improvement.
\end{abstract}

Keywords:-Coffea arabica L., genotypic correlation, path coefficient, phenotypic correlation and traits

DOI: $10.7176 / \mathrm{JEES} / 9-4-01$

Publication date: April $30^{\text {th }} 2019$

\section{Introduction}

The agricultural based Ethiopian economy is highly dependent on Arabica coffee. Around 31 percent of the country's foreign exchange income comes from this single commodity crop (FAO, 2014). In 2015/2016, Ethiopia exported around 180,000 tones of coffee at a value in excess of 800 million USD. As a result of this, Ethiopia is Africa's largest Coffee producer and the world's fifth largest Coffea arabica L. exporter next to Brazil, Vietnam, Colombia and Indonesia (ICO, 2016). It also provides significant employment opportunities in rural areas and sustains the livelihood of around 15 million in Ethiopia (Davis et al., 2012; ICO, 2016).

Despite the abundance of coffee genetic diversity and center of origin for Coffea arabica L., the productivity per unit area remained very low in Ethiopia with average national clean coffee yield of $670 \mathrm{~kg} \mathrm{ha}^{-1}$ (CSA, 2017). To overcome this problem, selecting traits that contribute directly and indirectly for yield improvement is prerequisite to identify high yielding genotypes. Correlation fosters the improvement of given traits as the positive correlation of traits is important in practical utility of selecting for a given trait as means to facilitate improving another trait. Such improvement depends on both genotypic correlation and phenotypic correlation of traits (Johnson et al., 1955).

Some findings done on Arabica coffee revealed that the existence of genotypic and phenotypic correlation between coffee yield and yield related traits. For example, Olika et al. (2011) and Gizachew and Hussein (2017) reported that plant height, canopy diameter, percentage of bearing primary branch and leaf length had positive genotypic correlation with green bean coffee yield. In line with this, Lemi et al. (2017) reported that strong positive phenotypic and genotypic correlation of green Coffee bean with main Stem diameter, number of nodes of main stem and canopy diameter.

The quantitative characters like yield performances of crop depend on many traits that encourage the crop improvement in yield. This requires another analysis method, path coefficient analysis that identifies traits that directly and indirectly contributing for the increment of yield. Thus, selection can be targeted on that trait to be effective in breeding works. The funding of Lemi et al. (2017) indicated that canopy diameter, average length and plant height had positive direct effect on Coffee bean yield, but negative direct effect of number of main stem nodes and Inter node length on yield. Similarly, Abdulfeta et al. (2018) has reported that leaf area, plant height, number of secondary branch and number of primary branch had positive direct effect on coffee bean yield, but exert negative effect on yield via length of primary branch. Hence, direct selection of these traits for 
yield improvement is effective during breeding program.

Additionally; for an effective selection based on yield related components, traits should be highly heritable and correlation among the components should be positive (Sidwell et al., 1976). Hence; Knowledge and Information on genotypic and phenotypic correlations among traits is crucial in planning, evaluating and setting selection criteria for the desired traits in breeding program (Johnson et al., 1955). Therefore, the objective of the present study is to determine the association among quantitative traits of some Wollega coffee genotypes for the next crop improvement program.

\section{Materials and Methods}

Description of Studying Areas

The experiment was conducted at Mugi agricultural research sub center which is the sub center of Jimma agricultural research center. Mugi located at $34^{\circ} 00^{\prime}$ to East and $8^{0} 40^{\prime}$ to North. It is located at altitude of $1570 \mathrm{~m}$ a.s.l and receive $1655 \mathrm{~mm}$ annual rain fall. Also, it has Nitosol soil type (Dubale, 2001) and minimum $17^{\circ} \mathrm{C}$ and maximum $29^{\circ} \mathrm{C}$ temperature for this location.

\section{Experimental Materials, Design and Agronomic practice}

The experiment was conducted during 2017/2018 cropping season, on 22 promising Wollega coffee accessions which were taken from different batch of base collections and four standards checks (Table 1).Randomized Complete Block Design in three replications was used. The study was superimposed on the already established coffee planted in July 2015 with six plants per plot at a spacing of $2 \mathrm{~m}$ by $2 \mathrm{~m}$ and $4 \mathrm{~m}$ between replications. Field management practices were performed as recommended (IAR, 1996).

Table 1. Passport data of promising Wollega coffee Accessions

\begin{tabular}{|c|c|c|c|c|c|}
\hline No. & Accessions & Districts & & Peasants Association & Collection altitude(m. a.s.l) \\
\hline 1 & W02/98 & Haru & & Wora Baro & 1740 \\
\hline 2 & W34/98 & Haru & & Wora Baro & 1790 \\
\hline 3 & W98/98 & Haru & & Chageli & 1800 \\
\hline 4 & W141/98 & Gimbi & & H.Giorgis & 1620 \\
\hline 5 & W163/98 & Gimbi & & Homa Arsama & $1600-1670$ \\
\hline 6 & W167/98 & Gimbi & & Homa Arsama & $1600-1670$ \\
\hline 7 & W175/98 & Gimbi & & Homa Arsama & $1600-1670$ \\
\hline 8 & W188/98 & Gimbi & & Homa Biribir & $1550-1600$ \\
\hline 9 & W191/98 & Gimbi & & Homa Biribir & $1500-1570$ \\
\hline 10 & W203/98 & Gimbi & & Siba Yesus & 1560 \\
\hline 11 & W212/98 & Gimbi & & Sibo Charo & 1560 \\
\hline 12 & W01/99 & Haru & & Guracha Holata & 1660 \\
\hline 13 & W40/99 & Haru & & Dogi Adere & 1720 \\
\hline 14 & W109/99 & Ayira Gliso & & - & 1600 \\
\hline 15 & W03/00 & Ayira Guliso & & Waro Seyo & 1500 \\
\hline 16 & W09/00 & Ayira Guliso & & Boke Keda & 1600 \\
\hline 17 & $\mathrm{~W} 50 / 00$ & Ayira Guliso & & Kurfessa birbir & 1580 \\
\hline 18 & W52/00 & Ayira Guliso & & Kurfessa birbir & 1520 \\
\hline 19 & W06/01 & Ayira Guliso & & Lalo Asella & 1600 \\
\hline 20 & W08/01 & Ayira Guliso & & Tosiyo mole & 1620 \\
\hline 21 & $\mathrm{~W} 15 / 01$ & Ayira Guliso & & Buro Hasabar & 1700 \\
\hline \multirow[t]{2}{*}{22} & W38/01 & Ayira Guliso & & Nebo Daleti & 1600 \\
\hline & Checks & & & & \\
\hline 1 & Mana sibu(W78/98) & & Haru & Haru & 1550 \\
\hline 2 & Sinde (W92/98) & & Haru & Haru & 1590 \\
\hline 3 & Chala (W76/98) & & Haru & Haru & 1740 \\
\hline 4 & Haru-I (66/98) & & Haru & Haru & 1800 \\
\hline
\end{tabular}

\section{Methods and Data Recorded}

Three plants were randomly selected from each plot for plant growth parameters. For yield and disease data, all plants per plot were used to record the necessary data. Data were recorded following the IPGRI Coffee descriptor (IPGRI, 1996). Data taken during the study were:-

Plan height (PH) (cm):- Height from the ground level to the tip of the main stem

Height up to first primary branch (HFPB) (cm):- Measurement of height above the ground up to the first primary branch

Total node number of main stem (TNN): - Counts of number of nodes on the main stem. 
Internodes length of the main stem (IL) (cm):- Computed as (TH-HFPB)/TNN-1, where TH = total plant height, HFPB =height up to first primary branch, TNN = total number of main stem nodes

Diameter of the main stem (DM) (mm):- Measured the diameter of the main stem at five $\mathrm{cm}$ above the ground using digital caliper

Number of primary branches (NPB):- Counted number of primary branches per main stem tree

Number of secondary branches (NSB):- Counted number of secondary branches (branches emerged from primary branches) per tree

Average length of primary branches (ALPB) (cm):- It was measured from the point of attachment to the main stem to the apex in $\mathrm{cm}$. Average length of four randomly selected undamaged primary branches per tree was used

Number of nodes per primary branch (NNPB):- Estimated as an average value of the four longest branches at the middle of the stem per plant

Number of bearing primary branches (NBPB):- Number of bearing primary branch counted per tree Percentage of bearing primary branches (PBPB) (\%):- It was computed per tree as (NBPB/NPB) * 100

Leaf length (LL) (cm):- Average length of five matured leaves (excluding 3 nodes from the terminal bud), measured from petiole end to apex of a leaf

Leaf width (LW) (cm):- Average width of five matured leaves (excluding 3 nodes from the terminal bud), measured at the widest part

Leaf area (LA) $\left(\mathbf{c m}^{2}\right)$ :- Calculated as: $\mathrm{LA}=\mathrm{K} * \mathrm{~L} * \mathrm{~W}$, LA is leaf area; $\mathrm{K}$ is constant specific to cultivars and canopy classes (0.67); L is leaf length $(\mathrm{cm})$ and $\mathrm{W}$ is leaf width $(\mathrm{cm})$ Yakob et al. (1998)

Canopy diameter (CD) (cm):- Average length of coffee tree canopy measured twice (east-west and north-south) from the widest portion of the tree canopy

Bean length (BL) (mm):- Measured as maximum length average of ten normal matured seeds.

Bean width (BW) (mm):- Estimated as average of ten normal matured seeds, measured at the widest

Bean thickness (BT)(mm): - Average of ten normal beans measured at the thickest part

Fruit length (FL) (mm):- Average of five normal matured green fruits, measured at the largest part

Fruit width (FW) (mm):- Average of five normal and matured green fruits measured at the widest

Fruit thickness (FT) (mm):- Average of five normal matured green fruits, measured at the thickest

Clean bean yield (YLD) (Kg/ha):- weight of fresh cherries per plot was recorded in gm and converted in to $\mathrm{kg} / \mathrm{ha}$.

Correlation and path coefficient analysis

Analysis of Variance and the five highest and lowest yielding genotypes based on phenotypic and genotypic correlation analysis were carried out using SAS version 9.0 software package (SAS Institute, 2004). Phenotypic (rp) and genotypic (rg) correlations were estimated as suggested by Miller et al. (1958). $\mathrm{rp}=\frac{P \operatorname{COV}(x, y)}{\sqrt{\sigma^{2} P_{x} * \sigma^{2} P_{y}}}$ Where, $\mathrm{rp}=$ phenotypic correlation coefficient, $\sigma^{2} \mathrm{px}=$ phenotypic variance for character $\mathrm{x}, \sigma^{2}$ py $=$ phenotypic variance for character $\mathrm{y}, \mathrm{rg}=\frac{G \operatorname{COV}(x, y)}{\sqrt{\sigma^{2} g x} * \sigma_{g y}^{2}}$ Where, $\mathrm{rg}=$ genotypic correlation coefficient, $\sigma^{2} \mathrm{gx}=$ genotypic variance for character $\mathrm{x}, \sigma^{2} \mathrm{gy}=$ genotypic variance for character $\mathrm{y}$.

Path coefficient analysis was calculated as Dewey and Lu (1959). The formula was as follows, $\mathrm{r}_{\mathrm{ij}}=\mathrm{P}_{\mathrm{ij}}+$ $\Sigma r_{i k} p_{k j}, r_{i j}=P_{i j}+\Sigma r_{i k} p_{k j}$, were ${ }_{r i j}=$ the association between the independent character (i) and dependent character (j) as measured by the correlation coefficient. $\mathrm{P}_{\mathrm{ij}}=$ Component of direct effects of the independent character (i) and dependent character ( $\mathrm{j}$ ) as measured by the path coefficient and, $\sum \mathrm{r}_{\mathrm{ik}} \mathrm{p}_{\mathrm{kj}}=$ Summation of components of indirect effect of a given independent character (i) on the given independent character (j) via all other independent character $(k)$. The residual effect $(\mathrm{h})$ was estimated by the following formula:- $\mathrm{h}=\sqrt{1-R^{2}}$ where, $\mathrm{R}^{2}=\sum \mathrm{P}_{\mathrm{ij}} \mathrm{r}_{\mathrm{ij}}$.

\section{RESULTS AND DISCUSIONS}

\section{Analysis of Variance}

Analysis of variance of traits indicated the existence of significance difference among genotypes. Morphological traits like Plant height $(\mathrm{PH})$, total node number of main stem (TNN), inter node length of main stem (IL), number of primary branch (NPB), number of bearing primary branch (NBPB), percentage of bearing primary branch (PBPB), fruit thickness (FT) and bean characters revealed significant difference among genotypes at $\mathrm{P}<0.01$ (Table 2). While the traits, height up to the first primary branch (HFPB), diameter of primary branch (DM), canopy diameter (CD), number of secondary branch (NSB), average length of primary branch (ALPB), number of node per primary branch (NNPB), leaf and fruit characters and yield showed significant difference among genotypes at $\mathrm{P}<0.05$. However, coffee leaf rust did not show any difference among genotypes. 
Table 2. Analysis of Variance of quantitative traits

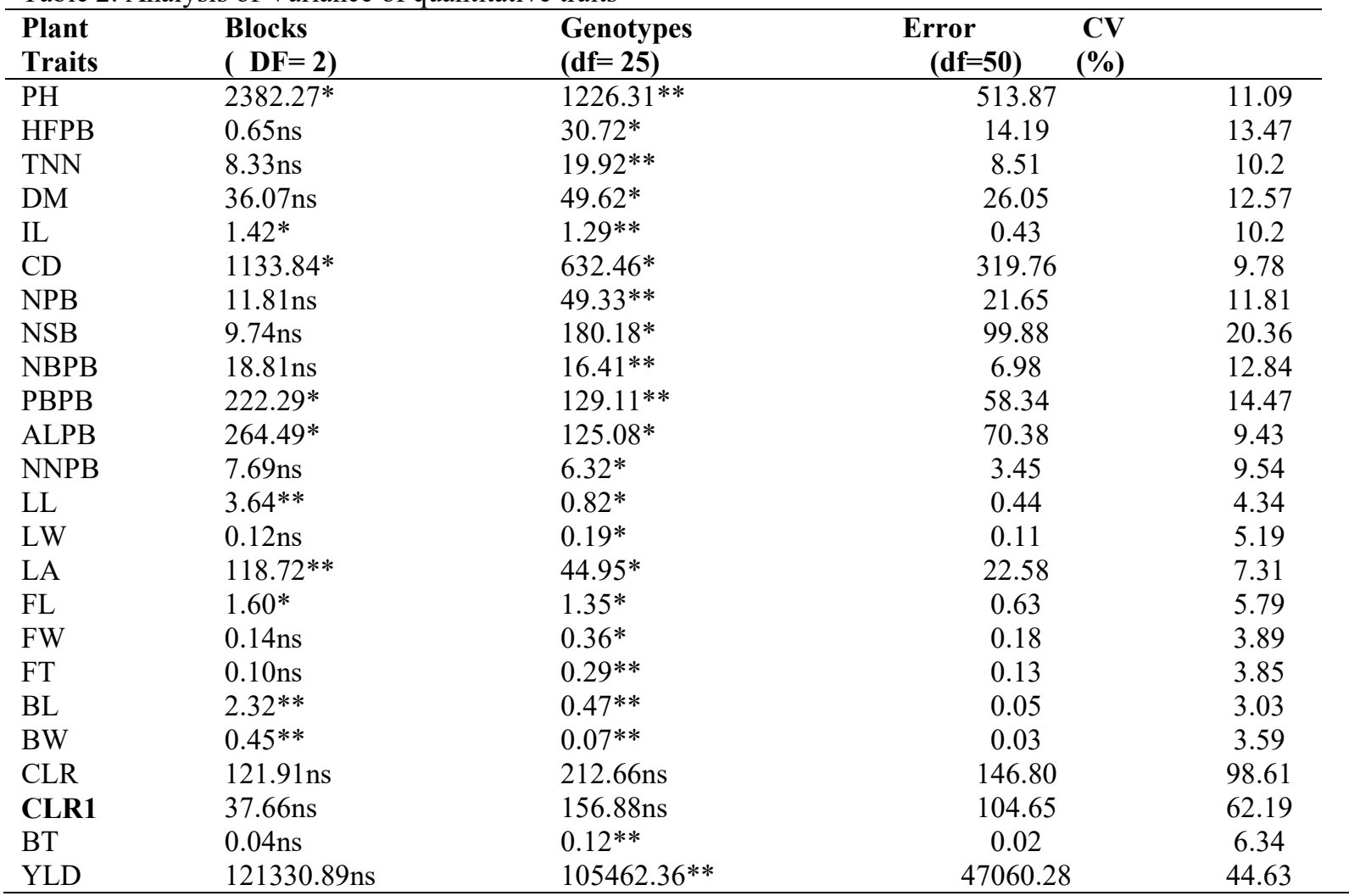

$*, * * \&$ ns- represent significant difference at probability level $0.05,0.01$ and non significant respectively. DFDegree of freedom, CV-Coefficient of variation, PH-Plant height $(\mathrm{cm})$, HFPB-Height up to the first primary branch $(\mathrm{cm})$, TNN-Total node number of main stem, DM-Diameter of main stem(mm), IL-Internodes' length of main stem $(\mathrm{cm})$, CD-Canopy diameter $(\mathrm{cm})$, NPB-Number of primary branch, NSB-Number of Secondary branch, NBPB-Number of bearing primary branch, PBPB-Percent of bearing primary branch, ALPB-Average length of primary branch $(\mathrm{cm})$, NNPB-Number of nodes per primary branch, LL-Leaf length (cm), LW-Leaf width $(\mathrm{cm})$, LA-Leaf area $\left(\mathrm{cm}^{2}\right)$, FL-Fruit length $(\mathrm{mm})$, FW-fruit width $(\mathrm{mm})$, FT-Fruit thickness (mm), BLBean length (mm), BW-Bean width (mm), BT-Bean thickness (mm), YLD-Yield (Kgha $\left.{ }^{-1}\right)$, CLR-Coffee leaf rust (\%) and CLR1- Arcsine transformed Coffee leaf rust data

\section{Phenotypic correlations}

The phenotypic correlations were presented in Table 3. Bean yield had positive phenotypic correlation with growth parameters such as PH, HFPB, TNN, DM, NPB, NBPB, ALPB, CD and NNPB. This implies that Genotypes with high bean yield are expected to have stronger (vigour) plants with wider stem diameter (DM) and possess more number of nodes on the main stem (TNN) and hence, more number of primary branches (NPB). Such genotypes also are expected to have taller coffee trees (PH). Primary branches are expected to possess many nodes and longer (NNPB and ALPB). Many of the primary branches should bear berries (NBPB and PBPB). Such genotypes logically have wider canopy (CD). The results obtained in this study are in agreement with the previous results obtained by Weverton et al. (2012). Also, Gizachew and Hussien (2017) reported positive phenotypic correlation of green bean yield to NPB and NBPB. However, CLR showed negative association (at phenotypic level) with IL, CD, ALPB, NNPB, bean thickness (BT), leaf length (LL) and HFPB at Mugi. This signified that genotypes having high height up to the first primary branch, longer leaves, primary branch emerging at distance from each other on main stem, longer primary branches and wider canopy diameter or having open growth habit are expected to be more resistant to CLR.

The five highest yielding genotypes had higher means of growth traits (PH, HFPB, TNN, DM, NPB, NBPB, $\mathrm{ALPB}, \mathrm{CD}$ and NNPB) as compared to the five lowest yielding genotypes which was expected from their positive correlation with yield (Table 4). The five highest yielding genotypes' green bean yield was increased by $157.3 \%$, PH by $19.9 \%$, TNN by $12.3 \%$, DM by $19.2 \%$, CD by $12.6 \%$, NPB by $14.1 \%$, NSB by $20.3 \%$, NBPB by $26.4 \%$ and $\mathrm{PBPB}$ by $13.3 \%$ as compared to the five lowest yielding. However, these elite genotypes had leaf rust infestation increased by $85.7 \%$. These increases were less than $10 \%$ in HFPB, ALPB and NNPB. For the five highest yielding genotypes' many of the leaf, fruit and bean traits were reduced; but these reductions were lower than $10 \%$ which is expected from their negative correlation(Table 4$)$. The largest reduction was that of BT $(8.3 \%)$ 
which is expected from its strong negative phenotypic correlation with green Coffee bean yield (Table 3 ). Similarly, Abdulfeta et al. (2018) reported negative association among yield and leaf traits at phenotypic level.

Table 3. Genotypic correlation coefficient (above diagonal) and phenotypic correlation coefficient (below diagonal) in Coffee genotypes

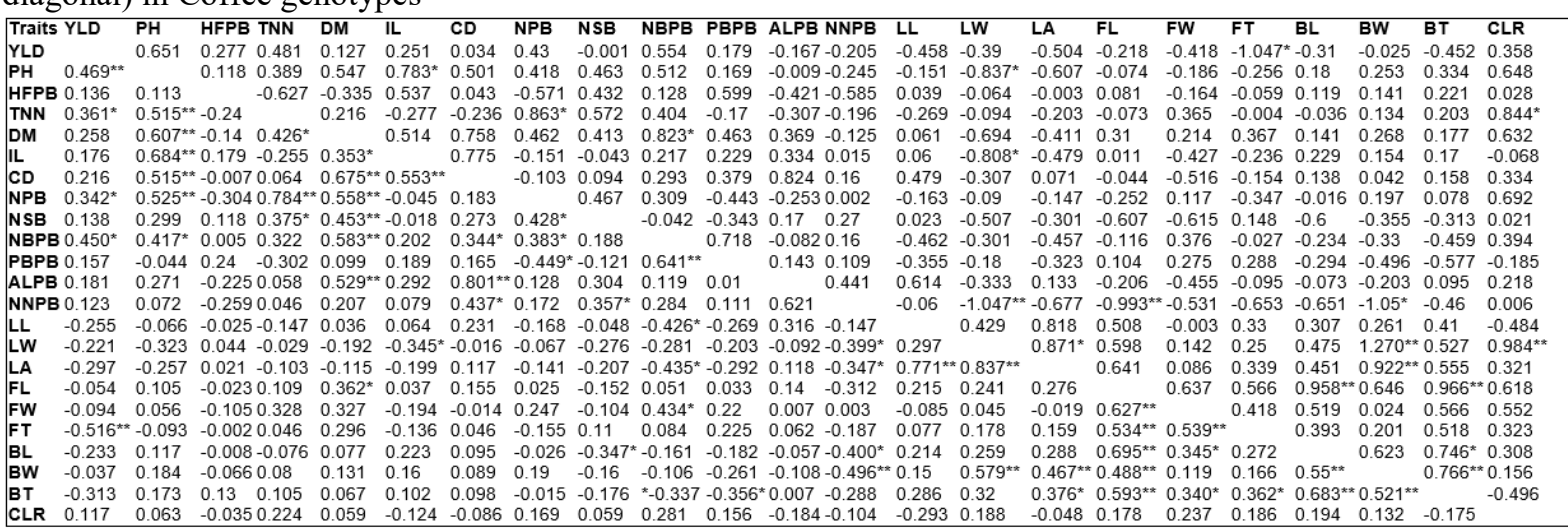

PH-Plant height $(\mathrm{cm})$, HFPB-Height up to the first primary branch $(\mathrm{cm})$, TNN-Total node number of main stem, DM-Diameter of main stem(mm), IL-Internodes' length of main stem $(\mathrm{cm}), \quad$ CD-Canopy diameter $(\mathrm{cm})$, NPBNumber of primary branch, NSB-Number of Secondary branch, NBPB-Number of bearing primary branch, PBPB-Percent of bearing primary branch, ALPB-Average length of primary branch $(\mathrm{cm})$, NNPB-Number of nodes per primary branch, LL-Leaf length $(\mathrm{cm})$, LW-Leaf width $(\mathrm{cm})$, LA-Leaf area $\left(\mathrm{cm}^{2}\right)$, FL-Fruit length $(\mathrm{mm})$, FW-fruit width $(\mathrm{mm})$, FT-Fruit thickness $(\mathrm{mm})$, BL-Bean length $(\mathrm{mm})$, BW-Bean width (mm), BT-Bean thickness (mm), YLD-Yield (Kgha ${ }^{-1}$, and CLR-Coffee leaf rust (\%)

Table 4. The five highest and lowest yielding genotypes based on phenotypic correlations

\begin{tabular}{|c|c|c|c|c|c|c|c|c|c|c|c|c|c|}
\hline & YLD & PH & HFPB & TNN & DM & IL & CD & NPB & NSB & NBPB & PBPB & ALPB & NNPB \\
\hline High & 745.3 & 228 & 28.4 & 31 & 44 & 6.7 & 193.6 & 42.1 & 53.3 & 22.5 & 54.5 & 92.6 & 19.4 \\
\hline Low & 289.7 & 190 & 28.1 & 27.6 & 36.9 & 6.1 & 171.9 & 36.9 & 44.3 & 17.8 & 48.1 & 85.4 & 18.7 \\
\hline Inc. & 455.6 & 37.9 & 0.3 & 3.4 & 7.1 & 0.6 & 21.7 & 5.2 & 9 & 4.7 & 8.4 & 7.2 & 0.7 \\
\hline$\%$ & 157.3 & 19.9 & 1.1 & 12.3 & 19.2 & 9.8 & 12.6 & 14.1 & 20.3 & 26.4 & 13.3 & 8.4 & 3.6 \\
\hline \multicolumn{14}{|c|}{ Table 4 Continued } \\
\hline & $\mathbf{L L}$ & & $\mathbf{L W}$ & LA & \multicolumn{2}{|l|}{ FL } & FW & FT & \multicolumn{2}{|c|}{ BL } & BW & BT & CLR \\
\hline High & 15 & & 6.3 & 63 & 13.8 & & 11 & 9.2 & \multicolumn{2}{|c|}{7.3} & 4.7 & 2.2 & 2.6 \\
\hline Low & 15.3 & & 6.4 & 65.7 & 13.6 & & 10.9 & 9.3 & \multicolumn{2}{|c|}{7.6} & 4.7 & 2.4 & 1.4 \\
\hline Inc. & -0.3 & & -0.1 & -2.7 & 0.2 & & 0.1 & -0.1 & \multicolumn{2}{|c|}{-0.3} & 0 & -0.2 & 1.2 \\
\hline$\%$ & -2 & & -1.6 & -4.1 & 1.5 & & $\begin{array}{l}0.9 \\
\end{array}$ & -1.1 & \multicolumn{2}{|c|}{-3.9} & 0 & -8.3 & 85.7 \\
\hline
\end{tabular}

PH-Plant height $(\mathrm{cm})$, HFPB-Height up to the first primary branch $(\mathrm{cm})$, TNN-Total node number of main stem, DM-Diameter of main stem(mm), IL-Internodes' length of main stem (cm), CD-Canopy diameter (cm), NPBNumber of primary branch, NSB-Number of Secondary branch, NBPB-Number of bearing primary branch, PBPB-Percent of bearing primary branch, ALPB-Average length of primary branch $(\mathrm{cm})$, NNPB-Number of nodes per primary branch, LL-Leaf length $(\mathrm{cm})$, LW-Leaf width $(\mathrm{cm})$, LA-Leaf area $\left(\mathrm{cm}^{2}\right)$, FL-Fruit length $(\mathrm{mm})$, FW-fruit width $(\mathrm{mm})$, FT-Fruit thickness $(\mathrm{mm})$, BL-Bean length $(\mathrm{mm}), \mathrm{BW}$-Bean width (mm), BT-Bean thickness (mm), YLD-Yield $\left(\mathrm{Kgha}^{-1}\right.$, and CLR-Coffee leaf rust $(\%)$ and Inc.-Increment

\section{Genotypic correlations}

At the genotypic level, green Coffee bean yield had positive correlation with PH, HFPB, TNN, DM, IL, CD, NPB, NBPB, PBPB and CLR (Table 3). It had negative correlation with NSB (near zero), with all leaf, fruit and bean traits. The correlation of green bean yields with fruit thickness (FT) was (-1.0) which was strong negative correlation. Although NSB had negative genotypic correlation near zero with green bean yield, it had positive association with PH, TNN, DM and NPB. Height up to the first primary branch was positively correlated with percentage of bearing primary branch. Also, CD had positive genotypic correlation with ALPB, LL, and NNPB. This result confirmed with the previous finding of Getachew et al. (2014) and Gizachew and Hussein (2017) who reported that the positive genotypic correlation of bean yield with $\mathrm{PH}, \mathrm{NBPB}, \mathrm{NPB}, \mathrm{CD}$ and positive association among each other.

On the genotypic level yield of the highest yielding genotypes was increased by $99.2 \%$, PH by $15.2 \%$, TNN by $9.4 \%$, DM by $13.2 \%$, NPB by $10.4 \%$, NBPB by $19.6 \%$ and PBPB by $9.7 \%$ which was expected from their positive correlation with green bean yield (Table 5). Although NSB had negative genotypic correlation with 
green bean yield, it was increased by $13.1 \%$ in the elite selections which may be due to its very weak negative association with yield. Average length of primary branch(ALPB) and NNPB were also increased by 5.4 and $2.1 \%$ although they were expected to decrease. This may be due to their weak negative correlation effect on green Coffee bean yield and strong positive correlation with other traits that had positive correlation with green bean yield. The reductions in leaf, fruit and bean traits were all lower than 5.0\%; the highest being that of BT $(8.3 \%)$ which is expected from their negative genotypic correlation effect on bean yield at this location (Table 3 ). At this location, CLR showed negative genotypic correlation with IL, LL, and BT.

The high yielding genotypes should possess smaller leaf length, narrow leaf area, smaller fruit and bean size in addition to possessing much number of primary branches, many bearing number of primary branch, many number of nodes per main stem, wider (vigour) main stem, distant internodes length and taller plant(height).

Table 5. The five highest and lowest yielding genotypes based on genotypic correlations

\begin{tabular}{|c|c|c|c|c|c|c|c|c|c|c|c|c|c|}
\hline & YLD & PH & HFPB & TNN & DM & IL & CD & NPB & NSB & NBPB & PBPB & ALPB & NNPB \\
\hline High & 678.3 & 222 & 28.3 & 30.4 & 43 & 6.7 & 190.6 & 41.4 & 51.9 & 22 & 54.1 & 91.3 & 19.4 \\
\hline Low & 340.5 & 194 & 28 & 27.8 & 38 & 6.2 & 175.4 & 37.5 & 45.9 & 18.4 & 49.3 & 86.6 & 19 \\
\hline Inc. & 337.8 & 29.4 & 0.3 & 2.6 & 5 & 0.5 & 15.2 & 3.9 & 6 & 3.6 & 4.8 & 4.7 & 0.4 \\
\hline$\%$ & 99.2 & 15.2 & 1.1 & 9.4 & 13.2 & 8.1 & 8.7 & 10.4 & 13.1 & 19.6 & 9.7 & 5.4 & 2.1 \\
\hline \multicolumn{14}{|c|}{ Table 5 Continued } \\
\hline & $\mathbf{L L}$ & & $\mathbf{L W}$ & LA & FL & & FW & FT & BL & & & $\overline{B T}$ & CLR \\
\hline High & 15.1 & & 6.3 & 63.6 & 13.8 & & 11 & 9.2 & 7.3 & 4 & & 2.2 & 2.5 \\
\hline Low & 15.3 & & 6.4 & 65.5 & 13.6 & & 11 & 9.3 & 7.5 & 4 & & 2.4 & 1.8 \\
\hline Inc. & -0.2 & & -0.1 & -1.9 & 0.2 & & 0 & -0.1 & -0.2 & 0 & & -0.2 & 0.7 \\
\hline$\%$ & -1.3 & & -1.6 & -2.9 & 1.5 & & $\mathbf{0}$ & -1.1 & -2.7 & 0 & & -8.3 & 38.9 \\
\hline
\end{tabular}

PH-Plant height $(\mathrm{cm})$, HFPB-Height up to the first primary branch $(\mathrm{cm})$, TNN-Total node number of main stem, DM-Diameter of main stem(mm), IL-Internodes' length of main stem $(\mathrm{cm})$, CD-Canopy diameter $(\mathrm{cm})$, NPB-Number of primary branch, NSB-Number of Secondary branch, NBPB-Number of bearing primary branch, PBPB-Percent of bearing primary branch, ALPB-Average length of primary branch $(\mathrm{cm})$, NNPB-Number of nodes per primary branch, LL-Leaf length $(\mathrm{cm})$, LW-Leaf width $(\mathrm{cm})$, LA-Leaf area $\left(\mathrm{cm}^{2}\right)$, FL-Fruit length $(\mathrm{mm})$, FW-fruit width $(\mathrm{mm})$, FT-Fruit thickness $(\mathrm{mm})$, BL-Bean length $(\mathrm{mm})$, BW-Bean width $(\mathrm{mm})$, BT-Bean thickness (mm), YLD-Yield (Kgha ${ }^{-1}$, and CLR-Coffee leaf rust (\%) and Inc.-Increment

\section{Path coefficient Analysis at Phenotypic level}

Path coefficient analysis was carried out using only eight traits (height up to first node, total node number of main stem, canopy diameter, number of bearing primary branches, average length of primary branch, fruit length, fruit width and fruit thickness) which explained $79.4 \%$ of the variability in green Coffee bean yield (Table 6). The full model consisting of 22 explanatory (independent) traits explained $97.3 \%$ of the variability in bean yield. Yield related traits like HFPB, TNN, NBPB, ALPB and FL had positive direct effect on green bean Coffee yield (Table 6). The highest positive direct effect exerted on green bean yield was that of NBPB (0.695)). This trait also had highly significant phenotypic correlation $\left(\mathrm{r}_{\mathrm{p}}=0.45^{* *}\right)$ with green bean yield. TNN $(0.342)$ also had positive direct effect and significant phenotypic correlation $\left(\mathrm{r}_{\mathrm{p}}=0.361^{*}\right)$ with bean yield. Height up to the first primary branch (HFPB) (0.294) and ALPB (0.549) also had positive direct effect on green bean yield although their phenotypic correlations with green bean yield ( $r_{p}$ of 0.136 and 0.181 , respectively) were statistically nonsignificant.

The indirect effects of all traits except HFPB, CD, FW and FT via ALPB were positive; that of NBPB being relatively very high (0.08). ALPB obtained its high positive direct effect from these positive indirect effects. Selecting plants with high NBPB will lead to selection of plants with high ALPB and indirectly to high green bean yield. This is as a result of selecting Coffee genotypes having high NBPB lead high ALPB which had positive direct effect on green bean yield. Although HFPB had positive correlation and positive direct effect on bean yield, the indirect effects of all traits on green bean yield via it except CD, NBPB, FW and FT were negative. Genotypes with very high HFPB should not be probably included when selecting those with high TNN and AFLP.

Canopy diameter (CD) had large negative direct effect $(-0.542)$ on green Coffee bean yield at the phenotypic level although it had positive phenotypic correlation $\left(r_{p}=0.216\right)$ with yield. The negative direct effect of $\mathrm{CD}$ on green bean yield resulted from the negative indirect effects on yield of all traits except HFPB and FW via $C D$. The indirect effect of ALPB was larger (-0.435). Canopy diameter would contribute positive effect on green bean yield because of its positive correlation with TNN, NBPB, ALPB, FL and FT. During direct selecting Coffee plants with high ALPB, one has to be conscious to include those with very wide canopy (large CD).

Fruit length had near zero negative phenotypic correlation $\left(\mathrm{r}_{\mathrm{p}}=-0.054\right)$ with green bean yield, but relatively strong positive direct effect $(0.520)$ with it. This resulted from positive indirect effects of all traits on green bean yield, except HFPB, via FL. Those of FW and FT were high. Since FW and FT had negative correlation with 
yield, it means that selecting genotypes with lower values of FW, FT and FL will lead to the identification of genotypes with higher green Coffee bean yield.

It can be summarized that under Mugi condition, the selection of Coffee accessions with high NBPB, TNN, and ALPB but with lower values of FW and FT would lead to the identification of high yielding genotypes. Genotypes with excessively high CD should be avoided from direct selection. The present result confirmed the finding of Getachew et al. (2014) and Lemi et al. (2017) who reported that direct positive effect of number of primary branches and inter node length of main stem on yield.

Table 6 .Estimation of direct (bold diagonal) and indirect effect (off diagonal) at phenotypic level of 8 traits on bean yield

\begin{tabular}{|cccccccccc|}
\hline Traits & HFPB & TNN & CD & NBPB & ALPB & FL & FW & FT & rp \\
HFPB & $\mathbf{0 . 2 9 4}$ & -0.082 & 0.004 & 0.004 & -0.124 & -0.012 & 0.051 & 0.001 & 0.136 \\
TNN & -0.071 & $\mathbf{0 . 3 4 2}$ & -0.035 & 0.224 & 0.032 & 0.056 & -0.159 & -0.028 & $0.361^{*}$ \\
CD & -0.002 & 0.022 & $\mathbf{- 0 . 5 4 2}$ & 0.239 & 0.44 & 0.081 & 0.007 & -0.028 & 0.216 \\
NBPB & 0.002 & 0.11 & -0.187 & $\mathbf{0 . 6 9 5}$ & 0.065 & 0.027 & -0.21 & -0.052 & $0.450^{* *}$ \\
ALPB & -0.066 & 0.02 & -0.435 & 0.082 & $\mathbf{0 . 5 4 9}$ & 0.073 & -0.003 & -0.038 & 0.181 \\
FL & -0.007 & 0.037 & -0.084 & 0.036 & 0.077 & $\mathbf{0 . 5 2 0}$ & 0.303 & -0.329 & -0.054 \\
FW & -0.031 & 0.112 & 0.008 & 0.302 & 0.004 & 0.326 & $\mathbf{- 0 . 4 8 3}$ & -0.332 & -0.094 \\
FT & -0.001 & 0.016 & -0.025 & 0.058 & 0.034 & 0.278 & -0.26 & $\mathbf{- 0 . 6 1 6}$ & $-0.516^{*}$ \\
\hline
\end{tabular}

Residual factors :- $\mathbf{0 . 2 0 6}$ rp -phenotypic correlation coefficient of average yield with the characters, HFPBheight to first primary branch; TNN- Total node number of main stem; CD - Canopy diameter (mm), NBPBnumber of bearing primary branches; ALPB- Average length of primary branches $(\mathrm{cm})$, FL-fruit length; FWfruit width(mm), FT-Fruit thickness(mm)

\section{Conclusion}

Analysis of variance indicated that the existence of significance difference between genotypes for almost all traits. Bean yield had positive phenotypic and genotypic correlation with plant height $(\mathrm{PH})$, total node number $(\mathrm{TNN})$, diameter of main stem (DM), canopy diameter (CD), number of primary branch (NPB), average length of primary branch (ALPB), percentage of bearing primary branch (PBPB) and number of bearing primary branch (NBPB). This indicated that selection of coffee genotypes with best performance in these traits are expected to increase green Coffee bean yield. However, leaf traits, fruit traits and bean traits showed negative genotypic and phenotypic correlation with green Coffee bean yield. From these traits, fruit thickness showed significant negative correlation with green bean yield. Hence, selections of high yielding genotypes are expected to have narrow leaf area, smaller leaf width, smaller fruit size and smaller bean size.

Canopy diameter manifested negative direct effect on Coffee bean yield, but showed positive phenotypic correlation with green bean yield. This positive association achieved via other traits mostly by ALPB and NBPB. Also, path coefficient analysis at phenotypic level revealed that ALPB, NBPB and TNN had positive direct effect and positive phenotypic correlation with yield. This indicated that direct selection of coffee genotypes that show better performance in these traits during yield improvement breeding program. The current result indicates that selecting genotypes with best performance in traits that showed positive correlation with green coffee bean yield will increase the overall coffee bean yield.

\section{Acknowledgement}

We would like to thank Ethiopian Institute of Agricultural Research for financial support of the study and Mugi and Haru Agricultural research sub center staff for their support during data collection.

\section{Reference}

Abdulfeta T, Hussein M, Ashenafi A. (2018). Correlation and Path Coefficient Analysis of some Coffee (Coffea arabica L.) Accessions using Quantitative Traits in Ethiopia. IJPBCS. 5: 383-390.

CSA (2017). Agricultural Sample Survey 2016/17. Report on Area and Production of Major Crops. April, 2017. Statistical Bulletin, Addis Ababa. 118p.

Davis AP, Gole TW, Baena S, Moat J. (2012). The impact of climate change on indigenous Arabica coffee (Coffea arabica L.): predicting future trends and identifying priorities. PLoS One 7:1-13.

Dewey DR, Lu KH. (1959). A correlation and path coefficient analysis of components of crested wheat grass seed production. Agro. J. 51: 515-518.

Dubale P. (2001). Soil and Water Resources and Degradation Factors Affecting their Productivity in the Ethiopian Highland Agroecosystems. Int.Conf. on African Dev. Archives.pp1-21.

FAO (2014). Analysis of price incentives for coffee in Ethiopia. Technical notes series, MAFAP, by Kuma Worako, T., MasAparisi, A. and Lanos B., Rome.

Getachew WM, Sentayehu A, Taye K. (2014). Genotypic correlation and path coefficient analysis of 
organoleptic quality attributes of some Ethiopian specialty coffee (Coffea arabica L.) accessions. Sky J. Agric. Res. 3: 46-52.

Gizachew A, Hussein M. (2017). Agro-Morphological Characterization of Sidama Coffee (Coffea Arabica L.) Germplasm Accession under its Specialty Coffee Growing Area, Awada, Southern Ethiopia. Int. J. Res. Sc., Eng. and Tech. 4:11-23.

IAR (1996). Recommended Production Technologies for Coffee and Associated Crops. Institute of Agricultural Research, Addis Ababa.18p.

ICO (2016). Historical Data on the Global Coffee Trade; http://www.ico.org/new- historical.asp, accessed on 20 July 2016.

IPGRI (1996). Descriptors for Coffea sp. \& Psilanthus sp, International Plant Genetic Resource Institute, Rome.35p.

Johnson HW, Robinson HF, Comstock RF. (1955). Genotypic and phenotypic correlation in Soya bean and their implication in selection. Agro. J. 47:477-483.

Lemi B, Ashenafi A, Tadesse B. (2017).Correlation and path coefficient analysis for yield and yield components in some Ethiopian accessions of Arabica coffee. IJPBCS. 4 :178-186.

Miller PA, Williams JC, Robinson HF, Comstock RE. (1958). Estimate of genotypic and environment variance in up land cotton and the implications and selections. Agro. J. 50:126-131.

RJ, Smith EL, McNew RW. (1976). Inheritance and interrelationships of grain yield and selected yield related traits in a hard red winter wheat cross. Crop Sci.16: 650-654.

SAS (Statistical Analysis System) software 2004. Version 9.0, SAS Institute, Cary, NC, USA.Sidwell

Weverton PR, Henrique DV, Dimmy HSG, Cássio V. (2012). Growth and yield of Coffea arabica L. in Northwest Fluminense: 2nd harvest1. Rev. Ceres, Viçosa V. 59: 809-815. 